\title{
Lack of expression of XIST from a small ring $X$ chromosome containing the XIST locus in a girl with short stature, facial dysmorphism and developmental delay
}

\author{
Darrell J Tomkins*,1, Helen L McDonald ${ }^{2}$, Sandra A Farrell ${ }^{3}$ and Carolyn J Brown ${ }^{2}$ \\ ${ }^{1}$ Department of Medical Genetics, University of Alberta and Cytogenetics Laboratory, Stollery Children's Hospital, \\ Edmonton, AB, Canada; ${ }^{2}$ Department of Medical Genetics, University of British Columbia, Vancouver, BC, \\ Canada; ${ }^{3}$ Department of Laboratory Medicine, The Credit Valley Hospital, Mississauga, ON, Canada
}

A 46,X, $r(X)$ karyotype was found in a three and a half year old girl with short stature, facial dysmorphism and developmental delay. The clinical findings were consistent with the phenotype described in a limited number of patients with small ring $X$ chromosomes lacking the XIST locus, a critical player in the process of $X$ chromosome inactivation. Surprisingly, in our patient, fluorescent in situ hybridisation demonstrated that the $X I S T$ locus was present on the ring X. However, expression studies showed that there was no XIST transcript in peripheral blood cells, suggesting that the ring $X$ had not been inactivated. This was confirmed by the demonstration that both of the patient's alleles for the androgen receptor gene were unmethylated, and that both of the patient's ZXDA alleles were expressed. The active nature of the ring $X$ would presumably result in overexpression of genes that may account for the developmental delay observed for the patient. Using polymorphic markers along the $X$ chromosome, the ring $X$ was determined to be of paternal origin with one breakpoint in the long arm between DXS8037 and XIST and one in the short arm in Xp11.2 between DXS1126 and DXS991. To attempt to determine why the XIST gene failed to be expressed, the promoter region was sequenced and found to have a base change at the same location as a variant previously associated with nonrandom $X$ chromosome inactivation. This mutation was not seen in over one hundred normal $X$ chromosomes examined; however, it was observed in the paternal grandmother who did not show substantial skewing of $\mathrm{X}$ chromosome inactivation. European Journal of Human Genetics (2002) 10, 44-51. DOI: 10.1038/sj/ejhg/5200757

Keywords: ring X; XIST; $\mathrm{X}$ chromosome inactivation; dosage compensation; Turner syndrome

Introduction

Ring X chromosomes have been recognised in girls with Turner syndrome, often with mosaicism for a 45,X cell line. In some instances, they are associated with mental retardation and a distinct phenotype of short stature, facial

*Correspondence: Dr DJ Tomkins, Department of Medical Genetics, 825 Medical Sciences Building, University of Alberta, Edmonton, AB T6G 2H7, Canada. Tel: (780) 407 1542; Fax: (780) 407 3059;

E-mail: d.tomkins@ualberta.ca

Received 14 August 2001; revised 21 November 2001; accepted 22 November 2001 dysmorphism characterised by long palpebral fissures, a relatively broad nasal root and tip, anteverted nares, a wide mouth with a thin upper lip, soft tissue syndactyly, and mental handicap. Careful cytogenetic characterisation of the ring $\mathrm{X}$ chromosomes has suggested that the smaller the size of the ring $\mathrm{X}$, the more likely are the findings of mental handicap and dysmorphic features in the patient. This has been attributed to failure of dosage compensation, by $\mathrm{X}$ chromosome inactivation, for the genes on the ring chromosome. $^{1-3}$

A region of the proximal long arm of the $\mathrm{X}$ chromosome is required in cis for inactivation of the chromosome, ${ }^{4,5}$ and 
contains the XIST gene, which is expressed exclusively from the inactive $X$ chromosome ${ }^{6}$ and is necessary for $X$ inactivation in mice (reviewed in Avner and Heard ${ }^{7}$ ). Smaller ring chromosomes may lack the XIST locus, rendering them functionally disomic for the genes present on the ring. ${ }^{8,9}$ The phenotype of individuals with small ring $\mathrm{X}$ chromosomes presumably results from the continued expression of genes in the pericentromeric region of the $\mathrm{X}$ chromosome due to failure of inactivation. ${ }^{10}$

In females, the presence of mosaicism for a ring $X$ lacking XIST has been correlated with mental retardation, facial dysmorphism often described as similar to the facies of Nikkawa syndrome, limb anomalies and abnormal pigmentation. ${ }^{8,11-17}$ Even more severe phenotypes have been reported, including prune-belly syndrome in a stillborn fetus with a ring $X$ lacking $X I S T^{18}$ and anencephaly and diaphragmatic hernia in a female fetus with a ring $X$ that was not characterised for XIST expression. ${ }^{19}$ In addition, there have been reports of males with a supernumary ring $\mathrm{X}$ chromosome, also lacking XIST, in some cases with a somewhat similar phenotype, including learning disabilities or mental handicap of varying severity, facial dysmorphism and digital anomalies. ${ }^{8,20-22}$

There are rare cases where a small ring containing the XIST gene has been observed associated with the ring $X$ phenotype. Many of these patients lack expression of the inactive X-specific transcript, which presumably precludes inactivation of the chromosome. ${ }^{9}$ We now report the characterisation of an additional case of a small ring $\mathrm{X}$ chromosome which includes the XIST locus but fails to express the gene. A mutation at a site previously associated with nonrandom X-chromosome inactivation was identified in the girl; however, the same change was found in her paternal grandmother who did not show substantial skewing of X-chromosome inactivation.

\section{Patient and Methods \\ Patient}

This girl presented with dysmorphic features, short stature and developmental delay. She was the first child of healthy nonconsanguineous, young, white parents. She was born at 37 weeks of gestation following an uncomplicated pregnancy. Birth weight was $2895 \mathrm{~g}$ ( $>25$ th percentile). Her neonatal course was complicated by hypoglycemia with no recognised specific cause. This resolved spontaneously. Milestones were somewhat delayed. She walked at 16 months, had a pincer grasp at 2 years, and used two to three word phrases by 3 years. When assessed using the Bailey Scales of Infant Development at 3 years, 7 months, level of function approximated that of a child of 2 years, 3 months. At 5.5 years, language skills were significantly delayed. She did not consistently recognise colors or letters of the alphabet. Social skills were immature. She was not able to pedal a tricycle.
When examined at 3.5 years, height of $89 \mathrm{~cm}$ and weight of $12.8 \mathrm{~kg}$ were just above the 3rd percentile. OFC of $50.5 \mathrm{~cm}$ was between the 50 th and 75 th percentiles. Inner canthal distance of $3 \mathrm{~cm}$ was proportionate to the OFC. Total hand and middle finger lengths were below the 3rd percentile, consistent with the clinical impression of brachydactyly. Facial appearance was distinctly dysmorphic (Figure 1). It was slightly asymmetric with left eye position lower than the right, and there was mild malar flattening. Ears were normal. Alveolar ridges were moderately thickened, although teeth were normal. Philtrum was poorly defined. Lower jaw was normal, although in infancy it had been described as being small. Hair pattern and neck shape were normal, as was chest shape. There was a clinical impression of short limbs but she did not cooperate with measuring this. Mild soft tissue syndactyly of right middle and index finger was seen, and there was significant soft cutaneous syndactyly of left 4 th and 5th toes. One large diffuse café au lait spot was seen on the right buttock, and a small one was present on the right knee. Otherwise, the examination was unremarkable.

Investigations showed a normal brain CT scan. Brachydactyly was seen on a radiograph of the upper limb at 9 months of age, but no other bony anomalies were noted. Renal ultrasound was normal at age 4 years of age, but a hypoplastic uterus was described. Echocardiogram was normal. TSH was normal. Cytogenetic testing was done at 3.5 and 4.5 years of age.

\section{Cytogenetic methods}

Peripheral blood specimens were set up for chromosomal analysis using routine methods, and metaphases were examined with GTG-banding. ${ }^{23}$ Fluorescent in situ hybridisation (FISH) was carried out according to supplier's protocol (Oncor, Gaithersburg, MD, USA), using probes for centromeric alphoid DNA sequences from X (DXZ1) or Y (DYZ3) chromosomes, and for the XIST locus. Fixed cells were saved for preparation of RNA to evaluate expression of the XIST gene.

\section{Molecular methods}

DNA was prepared by salt/SDS precipitation, ${ }^{24}$ while RNA was prepared by acid-guanidinium extraction. ${ }^{25}$ DNA and RNA was isolated from cells stored in fixative after cytogenetic analysis, blood, or cultured control cell lines, GM07348 (female), GM07033 (male), GM06563 (female with large ring $\mathrm{X}$ ) and GM07059 (female with non-random X inactivation), obtained from the Coriell Cell Repository. cDNA was synthesised as previously described. ${ }^{6}$ PCR amplification of DNA and cDNA used primers and conditions listed in Table 1 with $1 \mu \mathrm{M}$ primer, $20 \mu \mathrm{M}$ dNTPs and $10 \mathrm{U}$ Taq polymerase (Gibco-BRL) unless otherwise noted. Methylation of the androgen receptor $(A R)$ locus was analysed as has been previously described. ${ }^{26}$ For microsatellite analysis, PCR products were resolved on polyacrylamide gels and observed after staining with silver, while other PCR products were 
resolved on $2 \%$ agarose gels stained with ethidium bromide. The promoter region of XIST was amplified from the patient using XIST primers, U2 and H3, and purified product was sequenced using U2 and PM primers by the NAPS facility, UBC. A primer was designed with a mismatch (PM2, Table 1) to generate a $B a n I$ restriction enzyme site in the presence of the $-43 \mathrm{~A}$ variant base. After amplification with primers PM and PM2, PCR products were digested with $15 \mathrm{U}$ of BanI, and resolved on polyacrylamide gels. In the presence of the $-43 \mathrm{~A}, 16 \mathrm{bp}$ were removed from the end of the $145 \mathrm{bp}$

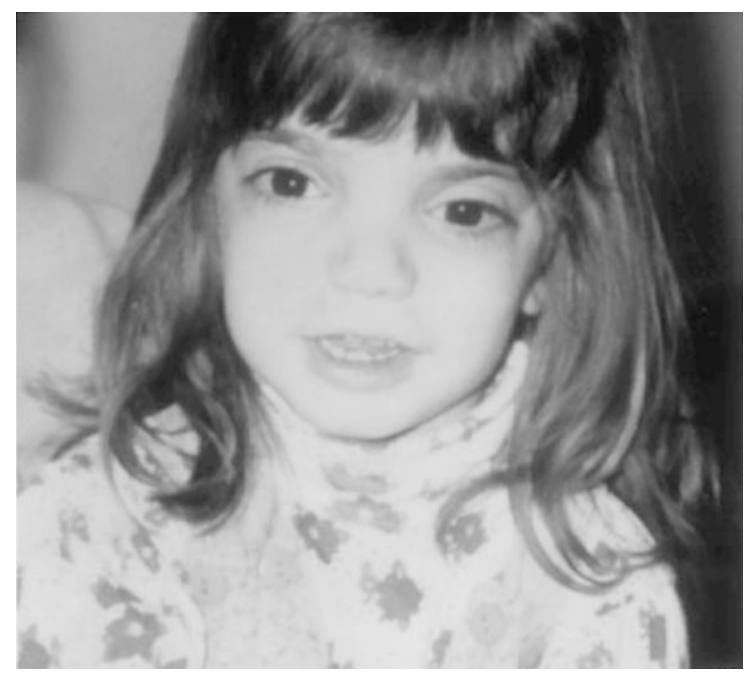

Figure 1 Facial appearance of the patient at 3.5 years. fragment. To examine methylation in this region, $1 \mu \mathrm{g}$ of DNA was digested with $15 \mathrm{U}$ of $\mathrm{HhaI}$ in a $20 \mu \mathrm{l}$ reaction. The reaction was then heated to $95^{\circ} \mathrm{C}$ for $5 \mathrm{~min}$ and then $1 \mu \mathrm{l}$ was amplified with primers PM and PM2. The PCR product was digested with BanI to distinguish between the two alleles.

\section{Results}

Cytogenetic analysis

GTG-banding analysis of the initial peripheral blood specimen showed mosaicism for two cell lines: $28 \%$ of the cells had $45, \mathrm{X} ; 72 \%$ had 46 chromosomes including one normal X chromosome and a small ring with bands consistent with an $\mathrm{X}$ chromosome origin (Figure $2 \mathrm{~A}$ ). A second blood sample 13 months later had the ring $X$ chromosome in all metaphases examined. FISH with $D X Z 1$ and $D Y Z 3$ showed that the marker was of $X$ chromosome origin (not shown). FISH with a DNA probe for the XIST locus demonstrated fluorescent signals on both the normal $\mathrm{X}$ and the ring $\mathrm{X}$ chromosomes (Figure 2B). The karyotype was designated 46,X,r(X) (p11.3q13).ish r(X)(XIST+).

\section{Activity of the $\mathrm{X}$ chromosomes}

As shown in Figure 3A, cDNA from the patient was amplified with primers for $P G K 1$, but no product was detected with primers for XIST. This result was similar to the amplification observed in males who do not have an inactive $X$ chromosome, while cDNA from female cells with a normal karyotype or containing a large ring $X$ chromosome (GM06563) showed amplification for XIST as well as the PGK1 control gene.

Table 1 Primers used in these analyses

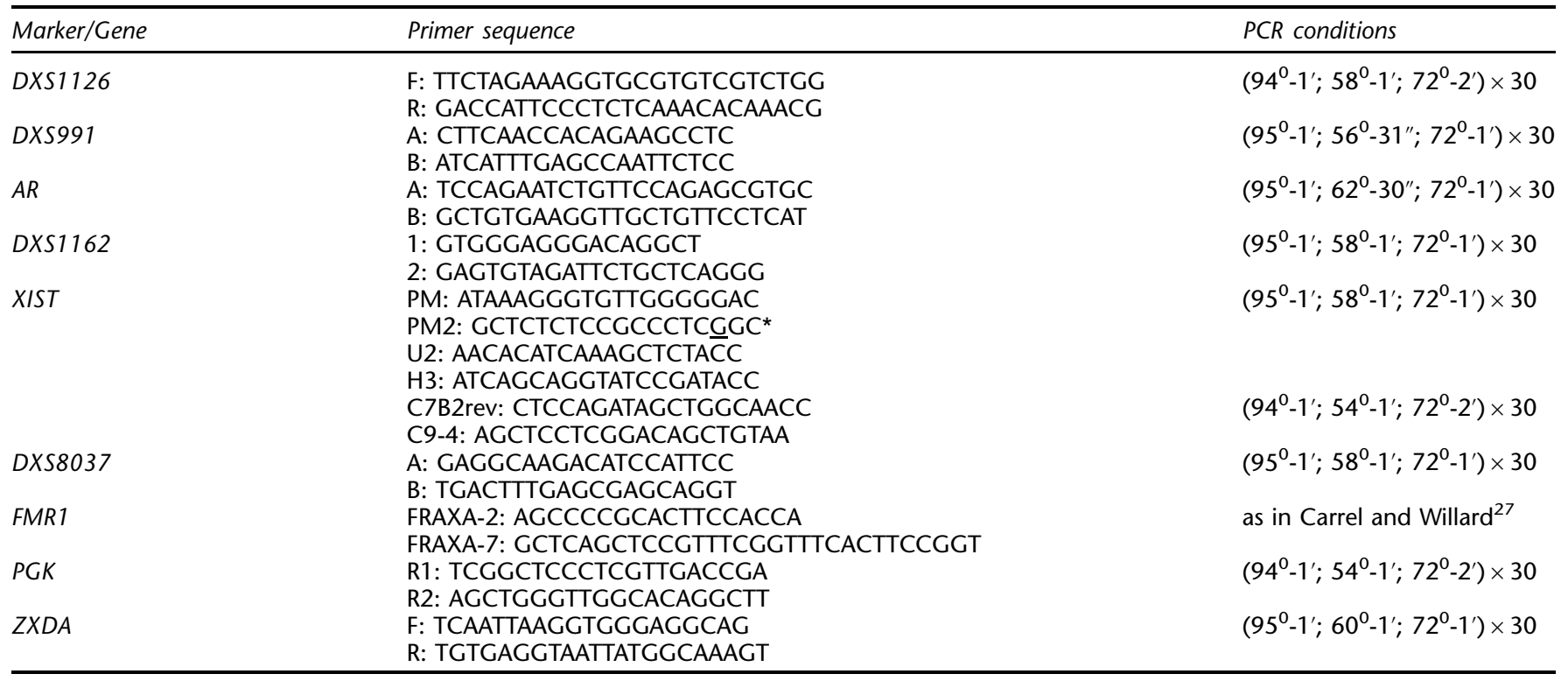

*Underlined nucleotide is changed in the primer to create a restriction enzyme recognition site. 
The patient was heterozygous for the polymorphic trinucleotide repeat in the androgen receptor (AR) gene, ${ }^{26}$ as shown by the presence of two bands in the uncut DNA in Figure 3B. After digestion with the methylation-sensitive restriction enzyme, HhaI, DNA from active (unmethylated) X chromosomes should be digested, eliminating the template for amplification. Amplification of both alleles in the patient was eliminated, suggesting that both alleles were unmethylated and active. In a control female cell line (GM07059) with

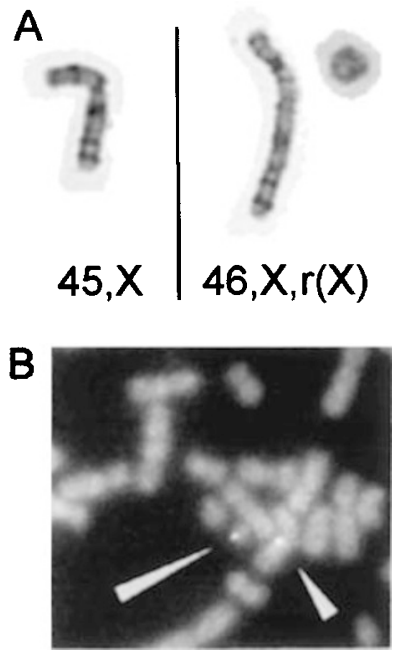

Figure 2 Cytogenetic analysis. (A) Partial karyotypes of GTGbanded chromosomes from the patient showing the single $X$ chromosome found in one cell line on the left, and the $X$ chromosome with the ring $X$ chromosome on the right. (B) $A$ metaphase following fluorescent in situ hybridisation with the $X I S T$ locus probe showing fluorescent signals on both the intact $\mathrm{X}$ chromosome (short arrow) and the ring $\mathrm{X}$ chromosome (long arrow).
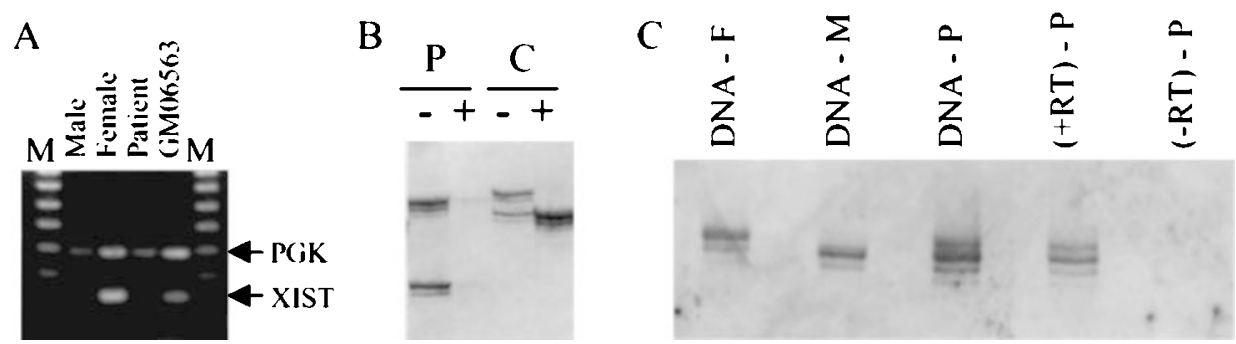

Figure 3 Activity of the $r(X)$. (A) Expression of XIST. cDNA from the patient as well as from a male, female, or large ring $X$ chromosomecontaining cell line (GM06563) was amplified with primers for the PGK1 (R1 : R2) and XIST (C9-4:C7B2rev) genes. The PGK1 product is larger and serves as a positive control for the presence of amplifiable cDNA. Both primer pairs flank exon/intron junctions and therefore amplify only CDNA, not DNA. Products were run on a $2 \%$ agarose gel with $100 \mathrm{bp}$ ladder as a size standard (M). (B) Methylation of androgen receptor $(A R)$. DNA from the patient $(P)$ or a control female cell line (C; GM07059) with non-random $X$ chromosome inactivation was amplified with primers for $A R$ with $(+)$ or without $(-)$ predigestion with the methylation-sensitive restriction enzyme Hhal. (C) Expression of ZXDA. DNA from the patient (P), her mother (M) and father (F) was amplified with primers flanking a CA repeat in the ZXDA gene. The paternal allele in the patient's DNA is fainter, consistent with the mosaic ring $X$ chromosome being paternally derived. cDNA from the patient showed a similar pattern of expression (+RT), while the control without reverse transcriptase ( $-\mathrm{RT})$ showed no amplification at all, demonstrating that the product was derived from amplification of cDNA, not contaminating DNA. 
A

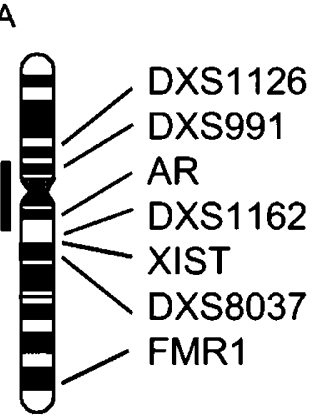

B
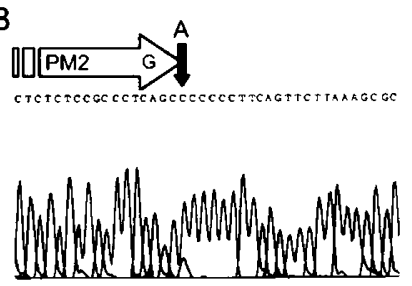

\section{2}

3

1

2

1

1

1
Father

Child

Mother

C

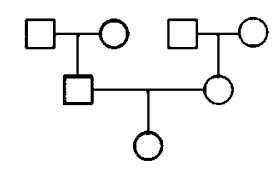

$-$

Figure 4 Molecular characterisation of the $r(X)$ chromosome. (A) Summary of polymorphic markers examined in the patient and her parents. Alleles are arbitrarily designated with the smallest allele observed in the family as ' 1 '. Only informative markers are shown. The heavy line to the left of the $X$ chromosome schematic delineates the presumed extent of the ring $(X)$ chromosome based on the loss of paternal alleles. (B) Sequencing of DNA amplified from the patient for the promoter of the XIST gene showed a base change as marked by the vertical arrow. A primer, PM2, was designed with a sequence change ( $G$ as shown in large arrow rather than $A$ ) that would generate a Banl restriction enzyme site in conjunction with the observed variant. (C) Detection of the change in family members (shaded) after amplification with primer PM2 and PM followed by digestion with Banl. The digested product (lower band) is $16 \mathrm{bp}$ smaller than products that are unable to be digested.

with the variant sequence being on the paternally inherited ring chromosome that is not present in all of her cells. The patient's paternal grandmother was heterozygous for the variant (Figure 4C). Over $100 \mathrm{X}$ chromosomes from male and female controls were examined for this variant using the BanI assay, and no other individuals were identified with the same change.

To determine the effect of this sequence alteration we examined the $\mathrm{X}$ inactivation status of the chromosome carrying the variant. The primers that recognise the variant basepair flank two methylation-sensitive enzyme sites, which are known to be differentially methylated on the active and inactive $\mathrm{X}$ chromosome ${ }^{29}$ (Figure $5 \mathrm{~A}$ ), making it possible to analyse methylation of the two XIST alleles individually. As shown in Figure 5B, predigestion with HhaI did not reduce the intensity of either the BanI cut (lower=variant) or uncut (upper=normal) alleles, suggesting that both XIST promoter region alleles are methylated. DNA from the patient's paternal grandmother (carrier, Figure 5B) amplified both alleles after predigestion, demonstrating that both the variant and normal alleles are unmethylated in a proportion of the grandmother's cells.

To confirm the inactivation of each $\mathrm{X}$ chromosome in a subset of the grandmother's cells, we examined methylation at the $A R$ locus. Both alleles were amplified after predigestion, with a slight alteration in intensity from the uncut sample (Figure 5C). Quantitation performed using the NIH IMAGE program with scanned gels for both $A R$ and XIST, suggest that the grandmother has $60 \%$ of cells with the variant on the active $\mathrm{X}$ chromosome.

\section{Discussion}

Chromosomal analysis of the patient was initiated because of short stature and mental handicap. The initial chromosome
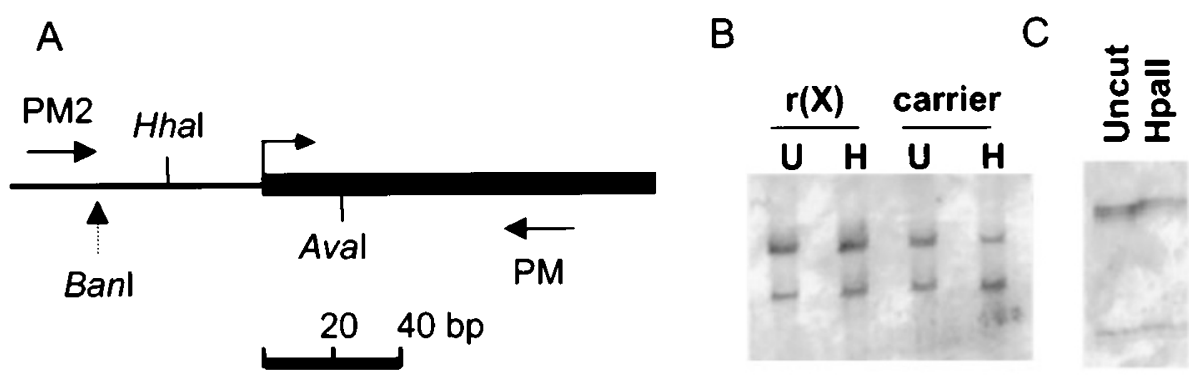

Figure $5 \mathrm{X}$ chromosome inactivation in females with the XIST promoter polymorphism. (A) Diagram of the promoter region of XIST showing the location of the variant identified by Banl, the transcription start site (bold line with arrow), and the location of two sites previously demonstrated to be differentially methylated on the active and inactive X chromosomes (Hhal and Aval). (B) Methylation of the XIST promoter was determined by comparing amplification of DNA before $(U)$, or after $(H)$, digestion with the methylation-sensitive restriction enzyme Hhal. The allele with the variant base was identified by digestion of the PCR product with Banl, which will cut the variant sequence (in conjunction with a base change introduced into primer PM2). The assay was performed with DNA from the patient with the ring $(X)$ chromosome $(r(X))$ or her paternal grandmother (carrier). (C) Methylation near the polymorphic trinucleotide repeat in $A R$ was examined by amplification of DNA from the paternal grandmother before (Uncut) or after (Hpall) digestion with the methylationsensitive restriction enzyme Hpall. 
result of $45, X / 46, X, r(X)(p 11.3 q 13)$ suggested the girl's phenotype might be explained by functional disomy of genes on the small ring $\mathrm{X}$ chromosome; however, FISH revealed that the XIST locus was present on the ring. Investigation of the expression of the XIST gene demonstrated no expression. The activity of the ring $X$ chromosome was confirmed by the lack of methylation at the $A R$ locus and by the expression of both $Z X D A$ alleles. The direct examination of gene activity on the ring chromosome using the expressed polymorphism in ZXDA should be valuable to resolve conflicts that have occasionally arisen in determining ring $\mathrm{X}$ activity using $\mathrm{AR}$ methylation or replication timing. ${ }^{30-32}$

There appears to be a general phenotype associated with active small ring $\mathrm{X}$ chromosomes that includes short stature and mental handicap. The short stature, which is also found in Turner syndrome, may be due to the absence of genes regulating stature such as SHOX (short stature homeoboxcontaining gene) in the pseudoautosomal region of the short arm of the X chromosome. ${ }^{33}$ The observed mental handicap specifically associated with the small active ring $\mathrm{X}$ chromosome is likely due to functional disomy for genes that are normally inactivated. Some of the considerable variation observed between individuals with ring $\mathrm{X}$ chromosomes might be related to the parental origin of the ring $X$, mosaicism or the size of the ring $\mathrm{X}$ chromosome.

Parental origin does not seem to correlate with outcome, ${ }^{34}$ although uniparental disomy (UPD) has been associated with a more severe outcome. ${ }^{30}$ This could reflect the duplication of an X chromosome after the time at which marking of an X chromosome to remain active occurs, thereby resulting in derivative chromosomes which are unable to inactivate. ${ }^{35}$ In the case reported here, the normal $\mathrm{X}$ chromosome was from the mother and the ring chromosome was derived from the father, which is not uncommon for rearranged $\mathrm{X}$ chromosomes (rings or isochromosomes). ${ }^{36}$ Thus, both chromosomes were present throughout early development and would be present at the time of inactivation.

Mosaicism is very large confounding factor in attempting phenotype-genotype correlations to define critical regions for different aspects of the 'syndrome'. Cytogenetic testing in our patient at different times showed different percentages of ring chromosome, demonstrating the difficulty in predicting levels of mosaicism from single samples of a single tissue. Rare cases where XIST expression has been detected with the more severe phenotype generally associated with an active ring chromosome ${ }^{12,30,37}$ may reflect the presence of active ring (X) chromosome at a critical stage in development.

The extent of DNA missing from the patient's ring chromosome was determined by allelotyping DNA from the patient and her parents. The breakpoint in Xp11.2 was between the DXS1126 and DXS991. Four of the five ring X chromosomes reported by Wolff et $a l^{8}$ had breakpoints between UBE1 and DXS423E, an approximately $10 \mathrm{Mb}$ region which would overlap the region defined for our proband.
Other rings retaining the XIST gene, but not expressing it, showed variable $\mathrm{Xp}$ breaks ${ }^{9}$ so the location of the short arm breakpoint does not seem to be related to inability to express $X I S T$. The breakpoint in the long arm in our case occurred between XIST and the nearby DXS8037 locus. Both loci are found within a single YAC, suggesting that they might be less than $1 \mathrm{Mb}$ apart. ${ }^{38}$ Two of the previous XIST-containing ring $\mathrm{X}$ chromosomes failing to express XIST also had breakpoints within $1 \mathrm{Mb}$ of XIST. The XIST gene is apparently intact in our patient, as a polymorphism was identified in the promoter that is telomeric to the $3^{\prime}$ end of the gene. ${ }^{39}$ While it is possible that more distal elements are required for proper XIST expression, two other XIST-positive non-expressing chromosomes contained substantially more distal DNA, even more than other rings expressing XIST. ${ }^{9}$

A sequence change was detected in the promoter of the XIST gene in the patient at position $-43 \mathrm{bp}$. Intriguingly, this is the same site associated with nonrandom $\mathrm{X}$ chromosome inactivation. ${ }^{40}$ The change in our patient was from $\mathrm{C}$ to $\mathrm{A}(\mathrm{C}-43 \mathrm{~A})$ while the previously reported change was to a $\mathrm{G}(\mathrm{C}-43 \mathrm{G})$. This base is not evolutionarily conserved, as a $\mathrm{G}$ is present in the mouse sequence and an $\mathrm{A}$ in rabbits. ${ }^{28}$ The C-43G variant was detected in two families, with skewing of inactivation ranging from more than 95\% inactivation of the chromosome with the variant in several individuals to only $55 \%$ skewing in others. The C-43A variant failed to undergo inactivation in the patient reported here, and was also associated with the active $X$ chromosome in the grandmother, although she showed only 60:40 skewing of inactivation. Furthermore, it has been reported that skewing increases with age. ${ }^{41}$ Thus, the extent of skewing in this individual is not different from that seen in the general population.

It is, however, clear that these variant sequences are not common in the population. We have examined over $100 \mathrm{X}$ chromosomes using the BanI assay described, which will detect both the C-43A and C-43G variants, and have not detected any additional cases. The two families were the only instances of the C-43G change in 1166 independent chromosomes. ${ }^{40}$ A recent analysis of 32 females with skewed inactivation also did not detect additional cases. ${ }^{42}$ Thus, it is surprising that these variants were detected in individuals with peculiarities in their $\mathrm{X}$ inactivation. Variability in the extent of inactivation might reflect interaction with other variable components of the inactivation pathway. It is also possible that the variability seen for the inactivation of the $\mathrm{X}$ chromosome carrying the C-43A variant was due to the chromosome being unable to lose the mark to remain active, in a manner analogous to imprinting center mutations. ${ }^{43}$ The HhaI assay used to search for the C-43G variant would not detect the C-43A variant, so it will be interesting to examine other females with nonrandom patterns of $\mathrm{X}$ inactivation for this variant. It will also be interesting to examine the promoter sequence of other ring $\mathrm{X}$ chromosomes failing to express XIST for this, or other, variants. 
In conclusion, we report a new case of a ring $X$ chromosome containing XIST, but failing to express it, resulting in the derivative chromosome remaining active. Functional disomy is presumed to account for the characteristic phenotype of dysmorphic features, brachydactyly and developmental delay. The presence of XIST on the small, active ring $X$ chromosome underscores the need to combine molecular analyses along with FISH for XIST in the analysis of such chromosomes. Detection of a variant sequence in promoter of XIST at the same position as another variant associated with nonrandom $\mathrm{X}$ chromosome inactivation is intriguing. However, the essentially random inactivation in grandmother with the same variant suggests that, if this change leads to failure to express XIST, the mechanism is complex.

\section{Electronic database information}

URLs for data in this article are as follows:

http://locus.umdnj.edu/higms/ for the Coriell Cell Repository.

http://rsb.info.nih.gov/nih-image/Default.html for the NIH IMAGE program.

http://www.ncbi/nlm/nih.gov/genemap/map.cgi?CHR=X for Genemap'99.

\section{Acknowledgments}

The family of our patient is thanked for their interest and cooperation. The assistance of Viola Freemen and Leslie Malloy, Regional Cytogenetics Laboratory, Hamilton Health Sciences Corporation, in preparation of cytogenetic figures is acknowledged. This research was supported by a research grant from the Medical Research Council of Canada (MOP13690) to CJ Brown.

\section{References}

1 Lindgren V, Chen C-p, Bryke CR, Lichter P, Page DC, Yang-Feng TL: Cytogenetic and molecular characterization of marker chromosomes in patients with mosaic $45, \mathrm{X}$ karyotypes. Hum Genet 1992; 88: 393-398.

2 van Dyke DL, Wiktor A, Palmer CG, et al: Ullrich-Turner syndrome with a small ring $\mathrm{X}$ chromosome and presence of mental retardation. Am J Med Genet 1992; 43: 996-1005.

3 Lyon MF: Gene action in the X-chromosome of the mouse (Mus musculus L.). Nature 1961; 190: $372-373$.

4 Therman E, Sarto GE, Palmer CG, Kallio H, Denniston C: Position of the human X inactivation center on Xq. Hum Genet 1979; 50: 59-64.

5 Brown CJ, Lafreniere RG, Powers VE et al: Localization of the X inactivation centre on the human $\mathrm{X}$ chromosme in Xq13. Nature 1961; 349: $82-84$.

6 Brown CJ, Ballabio A, Rupert JL et al: A gene from the region of the human $\mathrm{X}$ inactivation centre is expressed exclusively from the inactive X chromosome. Nature 1991a; 349: 38-44.

7 Avner P, Heard E: X-chromosome inactivation: counting, choice and initiation. Nat Rev Genet 2001; 2: 59-67.

8 Wolff D, Brown CJ, Schwartz S, Duncan AMV, Surti U, Willard HF: Small marker X chromosome lack the $\mathrm{X}$ inactivation center: implications for karyotype/phenotype correlations. Am J Hum Genet 1994; 55: 87-95.
9 Jani MM, Torchia BS, Pai GS, Migeon BR: Molecular characterisation of tiny ring $\mathrm{X}$ chromosome from females with functional $\mathrm{X}$ chromosome disomy and lack of cis X inactivation. Genomics 1995; 27: 182-188.

10 Zinn A, Page D, Fisher E: Turner syndrome: the case of the missing sex chromosome. Trends Genet 1993; 9: 90-93.

11 Kushnick T, Irons TG, Wiley JE, Gettig EA, Rao KW, Bowyer S: $45 \mathrm{X} / 46 \mathrm{X}, \mathrm{r}(\mathrm{X})$ with syndactyly and severe mental retardation. Am J Med Genet 1987; 28: 567-574.

12 Dennis NR, Collins AL, Crolla JA, Cockwell AE, Fisher AM, Jacobs PA: Three patients with ring (X) chromosomes and a severe phenotype. J Med Genet 1993; 30: 482-486.

13 McGinniss MJ, Brown DH, Burke LW, Mascarello JT, Jones MC: Ring chromosome $\mathrm{X}$ in a child with manifestations of Kabuki syndrome. Am J Med Genet 1997; 70: $37-42$.

14 Fritz B, Küster W, Ørstavik KH, Naumova A, Spranger J, Rehder H: Pigmentary mosaicism in hypomelanosis of Ito: further evidence for functional disomy of Xp. Hum Genet 1998; 103: $441-449$.

15 Stavropoulou C, Mignon C, Delobel B et al: Severe phenotype resulting from an active ring $\mathrm{X}$ chromosome in a female with a complex karyotype: characterisation and replication study. $J$ Med Genet 1998; 35: $932-938$.

16 Tümer Z, Wolff D, Silahtaroglu AN, Ørum A, Brøndum-Nielsen $\mathrm{K}$ : Characterization of a supernumerary small marker $\mathrm{X}$ chromosome in two females with similar phenotypes. Am J Med Genet 1998; 76: 45-50.

17 Matsuo M, Muroya K, Adachi M et al: Clinical and molecular studies in 15 females with ring $\mathrm{X}$ chromosomes: implications for $\mathrm{r}(\mathrm{X})$ formation and mental development. Hum Genet 2000; 107: $433-439$.

18 Guillen DR, Lowichik A, Schneider NR, Cohen DS, Garcia S, Zinn AR: Prune-belly syndrome and other anomalies in a stillborn fetus with a ring X chromosome lack XIST. Am J Med Genet 1997; 70: 32-36.

19 Nowaczyk MJM, Ramsay JA, Mohide P, Tomkins DJ: Multiple congenital anomalies in a fetus with $45, \mathrm{X} / 46, \mathrm{X}$ $\mathrm{r}(\mathrm{X})(\mathrm{p} 11.2 \mathrm{q} 12)$ mosaicism. Am J Med Genet 1998; 77: 306-309.

20 Duncan AMV, Macdonald A, Brown CJ, Wolff D, Willard HF Sutton B: Characterization of a small supernumerary ring $\mathrm{X}$ chromosome by fluorescence in situ hybridisation. Am J Med Genet 1993; 47: 1153-1156.

21 Callen DF, Eyre HJ, Dolman G et al: Molecular cytogenetic characterisation of a small ring $X$ chromosome in a Turner patient and in a male patient with congenital abnormalities: role of X inactivation. J Med Genet 1995; 32: 113-116.

22 Manea SR, Gershin IF, Babu A, Willner JP, Desnick RJ, Cotter PD: Mosaicism for a small supernumerary ring $X$ chromosome in a dysmorphic, growth-retarded male: $\operatorname{mos} 47, \mathrm{XXY} / 48, \mathrm{XXY},+\mathrm{r}(\mathrm{X})$. Clin Genet 1997; 52: $432-435$.

23 Rooney DE, Czepulkowski BH (eds): Human Cytogenetics. Constitutional Analysis. Oxford: Oxford University Press, 1992, Vol. 1, pp 93-96.

24 Miller SA, Dykes DD, Polesky HF: A simple salting out procedure for extracting DNA from human nucleated cells. Nucl Acids Res 1988; 16: 1215.

25 Chomczynski P, Sacchi N: Single-step method of RNA isolation by acid guanidinium thiocyanate phenol-chloroform extraction. Anal Biochem 1987; 162: 156-159.

26 Allen RC, Zoghbi HY, Moseley AB, Rosenblatt HM, Belmont JW: Methylation of HpaII and HhaI sites near the polymorphic CAG repeat in the human androgen-receptor gene correlates with $\mathrm{X}$ chromosome inactivation. Am J Hum Genet 1992; 51: 1229 1239.

27 Carrel L, Willard HF: Heterogeneous gene expression from the inactive $\mathrm{X}$ chromosome: an $\mathrm{X}$-linked gene that escapes $\mathrm{X}$ inactivation in some human cell lines but is inactivated in others. Proc Natl Acad Sci USA 1999; 96: 7364 - 7369. 
28 Hendrich BD, Plenge RM, Willard HF: Identification and characterization of the human XIST gene promoter: implications for models of X chromosome inactivation. Nucl Acids Res 1997; 25: $2661-2671$.

29 Hendrich BD, Brown CJ, Willard HF: Evolutionary conservation of possible functional domains of the human and murine XIST genes. Hum Mol Genet 1993; 2: 663-672.

30 Yorifuji T, Muroi J, Davai M et al: Uniparental and functional X disomy in Turner syndrome patients with unexplained mental retardation and X derived marker chromosomes. J Med Genet 1998; 35: $539-544$.

31 El Abd S, Patton MA, Turk J, Hoey H, Howlin P: Social, communicational, and behavioral deficits associated with ring X Turner syndrome. Am I Med Genet 1999; 88: 510-516.

32 Turner C, Dennis NR, Skuse DH, Jacobs PA: Seven ring (X) chromosomes lacking the XIST locus, six with an unexpectedly mild phenotype. Hum Genet 2000; 106: 93-100.

33 Rao E, Weiss B, Fukami $\mathrm{M}$ et al: Pseudoautosomal deletions encompassing a novel homeo box gene cause growth failure in idiopathic short stature and Turner syndrome. Nat Genet 1997 16: $54-63$.

34 Collins AL, Cockwell AE, Jacobs PA, Dennis NR: A comparison of the clinical and cytogenetic findings in nine patients with a ring (X) cell line and 16 45,X patients. J Med Genet 1994; 31: 528533.

35 Migeon B, Jeppesen P, Torchia B et al: Lack of X inactivation associated with maternal $X$ isodisomy: evidence for a counting mechanism prior to $\mathrm{X}$ inactivation during human embryogenesis. Am J Hum Genet 1996; 58: $161-170$.
36 Loughlin SAR, Redha A, McIver J, Boyd E, Carothers A, Connor JM: Analysis of the origin of Turner's syndrome using polymorphic DNA probes. J Med Genet 1991; 28: 156-158.

37 Migeon BR, Ausems M, Giltay J et al: Severe phenotypes associated with inactive ring X chromosomes. Am J Med Genet 2000; 93: $52-57$.

38 Mumm S, Jermak C, Waeltz P et al: 22-Mb integrated physical and genetic map based on YAC/STS content spanning the interval DSX1125-DXS95 in human Xq12-q21.31. Gene 1998; 208: $147-156$.

39 Lafrenière RG, Brown CJ, Rider $\mathrm{S}$ et al: $2.6 \mathrm{Mb}$ YAC contig of the human $\mathrm{X}$ inactivation center region in Xq13: physical linkage of the RPS4X, PHKA1, XIST and DXS128E genes. Hum Mol Genet 1993; 2: $1105-1115$.

40 Plenge RM, Hendrich BD, Schwartz C et al: A promoter mutation in the XIST gene in two unrelated families with skewed Xchromosome inactivation. Nat Genet 1997; 17: 353-356.

41 Busque L, Mio R, Mattioli J et al: Nonrandom X-inactivation patterns in normal females: lyonization ratios vary with age. Blood 1996; 88: 59-65.

42 Pereira LV, Zata M: Screening of the C43G mutation in the promoter region of the XIST gene in females with highly skewed X-chromosome inactivation. Am J Med Genet 1999; 87: 86-87.

43 Ferguson-Smith AC: Imprinting moves to the centre. Nat Genet 1996; 14: $119-121$. 